\title{
Expanding left ventricular assist device use to patients with disabilities: The role of assistive technology
}

\author{
Juan A. Crestanello, MD
}

\author{
From the Department of Cardiovascular Surgery, Mayo Clinic, Rochester, Minn \\ Disclosures: Author has nothing to disclose with regard to commercial support. \\ Received for publication July 26, 2018; accepted for publication July 26, 2018; available ahead of print Sept 7, \\ 2018. \\ Address for reprints: Juan A. Crestanello, MD, Department of Cardiovascular Surgery, Mayo Clinic, 200 First St \\ SW, Rochester, MN 55905 (E-mail: crestanello.juan@mayo.edu). \\ J Thorac Cardiovasc Surg 2019;157:e3-4 \\ $0022-5223 / \$ 36.00$ \\ Copyright (C) 2018 by The American Association for Thoracic Surgery \\ https://doi.org/10.1016/j.jtcvs.2018.07.079
}

\section{"Disability need not be an obstacle to success." -Professor Stephen W. Hawking ${ }^{1}$}

The 2017 Disability Statistics Annual Report estimates that $12.8 \%$ of the US population has 1 of the 6 major disabilities tracked by the US Census Bureau: ambulatory disability in $6.6 \%$, cognitive disability in $4.8 \%$, independent living disability in $4.5 \%$, hearing disability in $3.5 \%$, self-care disability in $2.5 \%$, and vision disability in $2.4 \% .^{2,3}$ Their prevalence increases with the age of the population. ${ }^{2,3}$ For example, although only $2.0 \%$ of the population between the ages of 18 and 64 years has a hearing disability, it increases to $9 \%$ between the ages of 65 and 74 years, and to $22 \%$ in patients older than 75 years. $^{2,3}$ According to the World Health Organization, people with disabilities seek more health care, encounter more barriers to health care, and have greater unmet health care needs than people without disabilities. ${ }^{1}$

Full cognitive, visual, auditory, and dexterity faculties are necessary to receive advanced medical therapies that require the active collaboration and participation of the patients in their care. Significant impairment of any of these faculties may became a barrier to receive a left ventricular assist device (LVAD) where patients not only have to take their medications but also interact with the LVAD device and its controller, respond to auditory and visual alarms and messages, charge and exchange batteries, change power sources, and provide care for the driveline. ${ }^{4}$ Patients receiving an LVAD require normal cognition, a normal or near normal vision to read the screen prompts and alarms, normal dexterity to exchange and charge batteries and plug the powerline, and normal or near normal hearing abilities to hear the alarms associated with malfunctions.

Assistive technology is defined as any device (item, piece of equipment, or product system) that is used to increase, maintain, or improve functional capabilities of individual with disabilities. ${ }^{5}$ Assistive technologies go from simple systems such as ramps, wheelchairs, and doors that open automatically to complex computerized devices that allow patients with speaking disability to talk. ${ }^{5}$

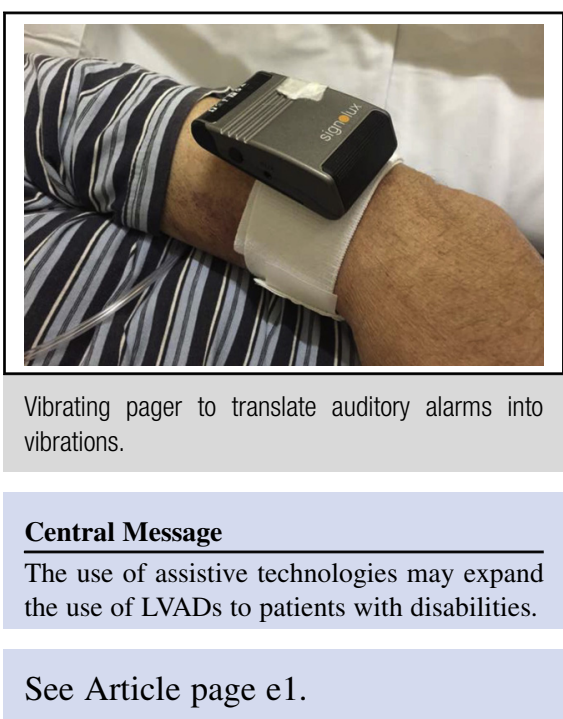

In this issue of the Journal, Spiliopoulos and colleagues ${ }^{6}$ report the creative use of assistive technology to overcome the hearing and speech disabilities of a patient requiring a HeartMate III LVAD (Abbott, St Paul, Minn). ${ }^{6}$ They used a commercially available device to make the LVAD alarms perceptible to the patient. Are disabilities a barrier to receive an LVAD and how common is this problem? The answers to these questions are not known. Although there are reported cases of patients with disabilities receiving or being denied a LVAD, the prevalence and severity of disabilities in patients receiving an LVAD and the number of patients considered not eligible because of a disability are unknown. ${ }^{7}$ However, the demographics of the more than 20,000 patients included in the Interagency Registry for Mechanically Assisted Circulatory Support suggests that a large percentage of patients considered for LVAD may have disabilities. ${ }^{8}$ In the Interagency Registry for Mechanically Assisted Circulatory Support, $45 \%$ of patients are 60 to 79 years of age. In this age group, the prevalence of disabilities in the general population ranges from $25.3 \%$ for ages 65 to 74 years to $49.6 \%$ for age 75 years and older. As such, it is likely that many patients with disabilities are denied this lifesaving treatment because of the lack of assistive technology to support the use of LVADs. Although LVADs may not be implanted in patients with severe cognitive disabilities, the development and incorporation of assistive technologies to current and future devices may allow the expansion of the use of LVADs in patients with severe hearing, visual, and speech disabilities. 


\section{References}

1. World Health Organization and World Bank. 2011 World Report on Disability. Available at: http://apps.who.int/iris/bitstream/handle/10665/70670/WHO_ NMH_VIP_11.01_eng.pdf;jsessionid=04F3E30BBFD85A82C26FA6878890017 D? sequence=1. Accessed July 20, 2018.

2. Erickson W, Lee C, von Schrader S. 2016 Disability Status Report: United States. Ithaca, NY: Cornell University Yang-Tan Institute on Employment and Disability (YTI); 2018. Available at: http://www.disabilitystatistics.org/StatusReports/2016PDF/2016-StatusReport_ME.pdf?CFID $=6944483 \&$ CFTOKEN $=b 76 f 3 \mathrm{c} 1213 \mathrm{feb}$ Oaf-08911ADA-9379-C288-D154E5192E259E4D\%20. Accessed July 20, 2018.

3. Kraus L, Lauer E, Coleman R, Houtenville A. 2017 Disability Statistics Annual Report. Durham, NH: University of New Hampshire; 2018. Available at: https:// disabilitycompendium.org/sites/default/files/user-uploads/2017_AnnualReport_ 2017_FINAL.pdf. Accessed July 20, 2018.
4. Thoratec Corporation. HeartMate 3 Left Ventricular Assist System Instructions for Use. Available at: https://www.accessdata.fda.gov/cdrh_docs/pdf16/P160054C. pdf. Accessed July 20, 2018.

5. Assistive Technology Act of 2004. Pub.L 108-364. Page 118 STAT. 1707. October $25,2004$.

6. Spiliopoulos S, Hergesell V, Dapunt O. Left ventricular assist device therapy in a patient with hearing and speech disabilities. J Thorac Cardiovasc Surg. 2019;157: e1-2.

7. Ravi Y, Firstenberg M, Crestanello J, Sudhakar CB. Mechanical circulatory support for the visually impaired: is it appropriate? Expert Rev Med Devices. 2011;8:155-7.

8. INTERMACS Quarterly Statistical Report 2017 Q3. Implant and event dates: June 23, 2006 to September 30, 2017. Available at: https://www.uab.edu/medicine/ intermacs/images/Federal_Quarterly_Report/Federal_Partners_Report_2017_ Q3.pdf. Accessed July 20, 2018. 